\title{
Psicanálise e Psicoterapia: o Fator da Sugestão no “Tratamento Psíquico"
}

\author{
Fernando Aguiar \\ Universidade Federal de Santa Catarina, SC, Brasil.
}

\begin{abstract}
Resumo: A noção de sugestão participa da fundação do campo psicanalítico e faz parte de seu vocabulário clínico. A rigor, pertence a sua pré-história, pois a história propriamente dita começa quando Freud abandona a hipnose. Em contrapartida, a explicação paulatina do fenômeno sugestivo foi sendo construída no decorrer da própria edificação teórica da disciplina freudiana, em particular depois de estabelecido seu vínculo com os conceitos psicanalíticos de transferência e de identificação. Esse percurso histórico permeado de reflexões imanentes, recorrentes e necessárias sobre o fenômeno, presentes desde o nascimento da psicanálise, tem seu apogeu em 1921, quando Freud, no trabalho sobre a psicologia das massas e análise do eu, chega a sua explicação definitiva. Levando em conta que a sugestão forma com a repetição e a resistência as três modalidades pelas quais se manifesta a transferência, este artigo busca apresentar subsídios para finalmente concluir com proposições sobre as diferenças clínicoepistemológicas fundamentais entre psicanálise e psicoterapia.
\end{abstract}

Palavras-chave: Sugestão, Transferência, Psicanálise, Psicoterapia.

\section{Psychoanalysis and Psychotherapy: Suggestion as a Factor in the "Psychological Treatment"}

\begin{abstract}
The notion of suggestion participates in the foundation of the psychoanalytic field and is part of its clinical vocabulary. Strictly speaking, such notion belongs to its prehistory, as the history of psychoanalysis only begins when Freud abandons hypnosis. However, the gradual elucidation of the suggestive phenomenon was built along the theoretical construction of psychoanalysis itself and, in particular, after establishing its link with the psychoanalytic concepts of transference and identification. This historical route (permeated by immanent, recurring and necessary reflections about this phenomenon that are present ever since the birth of psychoanalysis) has its peak in 1921, when Freud, in his work on group psychology and the analysis of ego, reaches its definitive explanation. Taking into account that suggestion forms, along with repetition and resistance, the three aspects through which transference manifests itself, this article seeks to present subsidies to finally conclude with propositions concerning the fundamental clinic-epistemological differences between psychoanalysis and psychotherapy. KeYwords: Suggestion, Transfer, Psychoanalysis, Psychotherapy.
\end{abstract}




\title{
Psicoanálisis y psicoterapia: la sugestión como factor en el "tratamiento psíquico"
}

\begin{abstract}
Resumen: La noción de sugestión participa en la fundación del campo psicoanalítico y es parte de su vocabulario médico. En sentido estricto, pertenece a su prehistoria, pues la historia comienza propiamente solo cuando Freud abandonó la hipnosis. En cambio, la explicación gradual del fenómeno sugestivo fue construyéndose durante la edificación misma de la disciplina freudiana, sobre todo después de establecer un vínculo con los conceptos psicoanalíticos de transferencia e identificación. Este recorrido histórico impregnado de reflexiones inmanentes, recurrentes y obligatorias sobre este fenómeno, presentes desde el nacimiento del psicoanálisis, tiene su punto álgido en 1921, cuando Freud, en el texto sobre la psicología de las masas y el análisis del yo, alcanza su explicación definitiva. Teniendo en cuenta que la sugestión junto con la repetición y la resistencia, forman las tres modalidades en que se manifiesta la transferencia, este artículo busca subsidios para finalmente concluir con proposiciones sobre las diferencias epistemológicas fundamentales entre la clínica psicoanalítica y la psicoterapia.

Palabras clave: Sugestión, Transferência, Psicoanálisis, Psicoterapia.
\end{abstract}

\section{Introdução}

Dicionarizado na língua francesa em 1900, graças talvez a J.-M. Charcot e H. Bernheim, o termo suggestibilité (como sugestionabilidade, em português) exprime a aptidão à sugestão, isto é, a tendência a se deixar facilmente influenciar. Suggestion, termo bem mais antigo na língua francesa-data do século XII, conforme ainda Le Petit Robert (1989) -, deriva do latim suggestio e, na Psicologia, nomeia uma crença, uma ideia, um desejo originário em outra consciência, sem que tal influência seja reconhecida pelo sugestionado. Por fim, suggestif (sugestivo), que designa o poder de sugerir ideias, imagens, sentimentos, e procede do inglês suggestive, to suggest, chega ao vocabulário francês em 1857. A partir de 1890, é também usado para indicar aquilo que sugere ideias eróticas.

Não por acaso, e na mesma década, a noção participa igualmente da fundação do campo psicanalítico e faz parte de seu vocabulário, mesmo se para ocupar em sua modalidade técnica mais radical, a sugestão (hipnótica) direta, o lugar de antítese clínica da associação livre. A rigor, pertence à pré-história da psicanálise, caso se considere que sua história propriamente dita começa quando Freud introduz a inovação técnica cuja particularidade consiste justamente em renunciar à hipnose (Freud, 2005/1914). Em contrapartida, se a sugestionabilidade tout court caracteriza e define todo tratamento psíquico, incluindo a invenção freudiana, seu entendimento não viria senão com o refinamento teórico da própria psicanálise, quando, sempre em meio a uma argumentação mais abrangente, Freud indica seu vínculo conceitual estreito com a transferência (1909, 1915-1917) e com a identificação (1921). Neste artigo, será privilegiada a relação entre sugestão e transferência, nos moldes das duas últimas aulas proferidas por Freud, na universidade, durante os anos da primeira guerra mundial.

James Strachey, o tradutor inglês da obra freudiana, observou que em sua língua, como na francesa, o uso técnico do termo "sugestão" decorreu da vida cotidiana; em alemão, ao contrário, sua introdução na linguagem habitual teria ocorrido depois de utilizado tecnicamente. O fato talvez justifique que, em 1921, ao denunciar a banalização crescente do termo, Freud afirme a necessidade de impor regras a seu uso convencional. Este artigo trata justamente de sua resposta (paulatina, pouco frequente e não intensiva) a este desafio, mediante as ferramentas conceituais conquistadas pela disciplina que ele próprio inventou. Como corolário, intenta-se ainda sublinhar, na esteira do exame do fenômeno da sugestão, as diferenças entre psicanálise e psicoterapia.

\section{Primeiras delimitações}

É esclarecedor recuar no tempo que antecede ao fundador da psicanálise.

Ellenberger (1994), cuja perspectiva histórico-continuísta em relação à descoberta do inconsciente é bem conhecida, afirma que sob denominações 
diversas a noção de sugestão foi referida por Platão (1989), no Ion, como "entusiasmo", e por Montaigne (1962), em De la force de l'imagination, como "imaginação" - ou imaginatio, como então chamavam em latim. O autor, médico psiquiatra ehistoriador das ciências, menciona o enorme interesse que, na época da Renascença, os filósofos e os médicos tiveram por tal "poder do espírito", cujos estudos concomitantes resultaram em inúmeras obras, muito conhecidas na época e hoje esquecidas.

Em um capítulo de seus Ensaios, Montaigne (1940) resume algumas das ideias de seu tempo sobre esse assunto. A imaginação explica os efeitos contagiosos das emoções humanas (e) é causa frequente de doenças físicas e mentais; ela pode mesmo causar a morte, assim como todos os efeitos habitualmente atribuídos à magia. A imaginação pode produzir fenômenos físicos singulares, tais como os estigmas, e mesmo a transformação de um sexo em outro. Mas a imaginação também pode ser utilizada para curar as doenças físicas e mentais (Ellenberger, 1994, p. 141).

Mais próximo de nós, falamos em magnetismo animal (Mesmer), fascinação (Donato), hipnose (Braid e Charcot), sugestão e autossugestão (Bernheim). Com o conceito de transferência, a teoria rigorosa desenvolvida por Freud marca e assegura um grau superior de legitimidade teórica, integrando a sugestão à repetição e à resistência - com efeito, as três vertentes pelas quais se manifesta, no enquadramento clínico, o fenômeno transferencial (Miller, 1987). "Sem dificuldade reconhecemos [na transferência] o mesmo fator dinâmico, chamado de sugestionabilidade pelos hipnotizadores e que é o vetor da relação hipnótica [...]" (Freud, 1992/ 1925, p. 89). Mannoni (1980, pp. 49-50) resume tudo de maneira muito feliz ao escrever que a transferência é o restolho da possessão, obtida mediante uma série de subtrações: "Elimina-se o diabo, permanecem as convulsionárias. Eliminam-se as relíquias, permanecem os 'magnetizados' de Mesmer. Elimina-se o baquet, temos a hipnose e a 'relação'. Elimina-se a hipnose, permanece: a transferência".

Em seu sentido amplo, e conforme a definição sucinta de Marie (2004), a transferência é uma inclinação espontânea, irredutível e fundante da experiência humana, e que diz respeito a uma alteridade subjetivada à qual nos assujeitamos, antecipadamente, mediante um vínculo imanente e imediato. Na vida cotidiana, tais manifestações (ditas de transferência com a psicanálise) constituem um aspecto importante da influência que exerce o político sobre os eleitores, o professor sobre os alunos, o orador sobre os auditores, o médico sobre os pacientes... São, em particular, as mesmas manifestações que em todas as épocas sustentaram e animaram as práticas curativas dos feiticeiros, dos xamãs, dos fazedores de milagres de todas as religiões, dos mesmeristas, dos hipnotizadores e de tantos outros que na atualidade praticam o que genericamente chamamos de "psicoterapia". Ora, em vez de psicoterapia, Freud optou pelo neologismo psicanálise para batizar o seu próprio método; e tratamento psíquico (ou anímico) deu nome a um de seus textos pré-psicanalíticos, precoce e importante, a ponto de durante décadas ser dado como de 1905. Em uma palavra, o tratamento psíquico constitui para Freud uma abordagem com fins curativos de padecimentos físicos ou psíquicos despertados pela vida anímica, através de procedimentos que atuam em primeiro lugar e de imediato na alma humana - para Freud, "[...] a mais antiga terapia da qual se serviu a medicina”. Vale destacar (em outro texto, este sim de 1905) sua fina e sincera observação: “[...] a fim de curá-los, colocavam-se os doentes num estado de 'expectativa crédula', que nos presta ainda hoje os mesmos serviços" (Freud, 2006a/1905, pp. 47-48). Contudo, acrescentava naquele início do século passado: "A numerosos médicos a psicoterapia aparece, ainda hoje, como um produto do misticismo moderno".

Historicamente, as psicoterapias estiveram articuladas desde sempre à religião de uma dada comunidade. Libertaram-se nos tempos modernos ao construir em troca uma concepção de homem ao menos em parte consonante com o espírito do tempo, ou mais precisamente, com a atmosfera científica reinante (Marie, 2004). Não seria assim incorreto afirmar que A. Mesmer inaugura esta fase nos tempos modernos: em pleno "século das luzes" e supostamente apoiando-se na teoria física do magnetismo, teria vencido a disputa com o último dos exorcistas, o padre Johann Joseph Gassner (Ellenberger, 1994). Ambos, como tantos outros ao longo da história, são precursores dos nossos atuais psicoterapeutas.

"Nós aprendemos a utilizar para esse fato a palavra 'sugestão'...” (Freud, 2006b/1905, p. 48). Mas a Freud - medíocre hipnotizador - não passou despercebido o papel fundamental desempenhado pela disposição psíquica do paciente em se deixar sugestionar; logo, no limite, o efeito sugestivo provém muito menos do sugestionador que do sugestionado. Por isso, fator ora favorável ao tratamento, ora de efeito inibidor, é de toda maneira sua influência que perpassa e define todo o tratamento psíquico: "Moebius nos ensinou que a 
ausência de confiabilidade que deploramos em tantos de nossos métodos de tratamento deve ser atribuído justamente à ação perturbadora exercida por esse poderoso fator" (Freud, 2006b/1905, p. 48).

Em termos fenomenológicos, nenhum médico o desconheceu, mas, quando a oportunidade se apresenta, Freud jamais se furta a esclarecer em que medida, com procedimentos fundados na transferência, o psicanalista é capaz de romper com a prática de seus congêneres, precursores ou coetâneos, sejam eles confessores católicos, médicos ou modernos psicoterapeutas. Conta a seu favor a ventura de dispor em sua clínica do conceito de transferência, que, englobando o fator da sugestionabilidade, a ele não se reduz por princípio: seu método, como vimos, leva em conta também a resistência e a repetição, os quais, cada uma à sua maneira, lhe são antípodas. Ainda a mencionar o ganho clínico inequívoco propiciado pela articulação elegante e congruente deste conceito fundamental com seus pares na rede conceitual psicanalítica, enquanto a sugestionabilidade era tomada estultamente por Bernheim como um fenômeno originário, um fato fundamental na vida psíquica que prescindia de explicação.

\section{Das rupturas freudianas}

Para construir a própria clínica, Freud, clínico à contrecoeur, mas, ao mesmo tempo, rigoroso e inventivo, produziu rupturas. A primeira delas ocorre, nos últimos anos do século XIX e pela via aberta por Charcot, quando opta pelo tratamento psíquico, logo, pela sugestão, e pela hipnose, práticas então no mínimo heterodoxas na medicina. Como se sabe, na era moderna, a objetividade médica fundou-se na observação empírica do processo e desenvolvimento de doença no corpo, e na possibilidade, de o conhecimento daí resultante ser aplicado num outro corpo nas mesmas condições. Materializado na observação minuciosa de uma lesão no cadáver - de fato, seu objeto fundante de estudo, que obviamente não fala senão por seus estigmas -, o desprezo relativo pela palavra do paciente é assim herança constitutiva da clínica médica, instituída conforme esse ponto de vista hegemônico no Ocidente.

Ainda hoje, na ação clínica quotidiana, não raro temos um médico frente a uma doença e não frente a um sujeito doente; e mesmo que em nossos dias esse médico não mais desconheça ou recuse a primordialidade da "relação médico-doente", haver-se com tal posição lhe impõe dificuldades consideráveis em sua prática cotidiana (Le Guen, 1989). No entanto, para Freud (2006b, p. 49), em 1905, referindo-se em particular ao campo que era o seu, "não se trata de um discurso moderno, mas de um adágio dos antigos médicos [...]: não é o medicamento que cura esses doentes [psiconeuróticos], mas o médico, isto é [...] a personalidade do médico, na medida em que, através dela, ele exerce uma influência psíquica". Assumindo sua condição de "tratamento psíquico" (melhor dizendo, método investigativo com consequências clínicas), a psicanálise, ao privilegiar justamente a escuta e o ato analítico nos limites impostos por sua regra fundamental, coloca o analisando em ação e no centro do tratamento - mesmo porque quem escuta não pode mais se constituir como a referência central e absoluta, e como "o único juiz e o único garantidor de seu saber" (Le Guen, 1989, p. 12).

Um segundo momento da ruptura freudiana visaria à própria ideia de certo tratamento psíquico, que, no limite ou ao menos próximo das mais variadas formas de charlatanismo, utiliza maciçamente e de maneira não crítica o artifício técnico da sugestão. Em termos cronológicos, "se o método catártico [Breuer] já renunciara à sugestão" - de fato, tal renúncia diz respeito ao "tratamento pela sugestão hipnótica", que se funda na sugestão direta do terapeuta contra a manifestação de sintomas (Freud, 2006c/1904, p. 12) - coube a Freud dar o passo seguinte e abandonar também a hipnose: "devemos notar que, em nossa técnica, abandonamos a hipnose somente para redescobrir a sugestão sob a forma de transferência" (Freud, 2000/1915-1917, p. 463).

Assim, sem a ambivalência da clínica médica anatômica, a psicanálise admite de bom grado - por razões técnicas, mas também éticas - esta influência inevitável que em toda relação assimétrica um exerce sobre outrem. É o que veremos a seguir, não sem antes ressaltar que sua abordagem do fenômeno não o reduz à positividade, à linearidade e ao participativo, como parecem supor, na outra ponta do espectro, tantas psicoterapias. Em outras palavras, o conceito de transferência não está fundado num ideal relacional, pois, se constitutivo, universal, estrutural e estruturante da condição humana, sua manifestação clínica constitui também um obstáculo ao tratamento, no limite, muito mais que seu facilitador. Como recomenda Freud em Recordar, repetir e perlaborar, de 1914, unicamente seu pronto e paciente manejo permite fazer com tudo isso sua mola-mestra. 
Em contrapartida, e intramuros na própria psicanálise, um esquecimento parece incidir no fato de que em todo ato clínico, psicanalítico ou não, os efeitos sugestivos que lhe são inerentes tendem a predominar, por definição, sobre a relação suposta de transferência. Daí ser preciso ter claro que, embora o conceito de transferência abranja fatos clínicos que não se limitam ao previsto pela noção de sugestionabilidade, tal distinção não se dá a conhecer de maneira natural. Trata-se antes de uma operação singular, a ser constantemente e a cada vez apreendida com a experiência - e que Freud chamou de manejo ou manobra da transferência (Handhabung der Übertragung), essencial ao processo de perlaboração (Durcharbeitung) do paciente. Por sua vez, perlaboração é o processo pelo qual a análise vai paulatinamente integrando interpretações, uma espécie de "trabalho psíquico", que, constante no tratamento, pode sofrer uma intensificação em períodos de fortes resistências. A expectativa é que este processo, prenhe de idas e vindas e jamais linear, "permita ao sujeito aceitar certos elementos recalcados, [liberando-se] da influência dos mecanismos repetitivos" (Laplanche, \& Pontalis, 1973, p. 305).

Em uma palavra, sabemos com a psicanálise que, para ser coerente com sua própria definição, a extensão conceitual da sugestionabilidade (termo da predileção de Freud) circunscreve apenas a modalidade positiva (terna, fraterna, cooperadora) da transferência. Necessária, mas insuficiente, em certos casos, esta chega a ser encobridora: “[...] mesmo os mais belos resultados eram como que bruscamente apagados se a relação pessoal com o paciente fosse perturbada" (Freud, 1992/1925, pp. 74-76). Por isso, na clínica sugestiva, advertida ou não, a ela se impõe necessariamente denegar a transferência sexual, por um lado, e por outro excluir de seu horizonte, mediante toda sorte de concessões (antitéticas, portanto, à "abstinência”, a "outra” regra da psicanálise recomendada por Freud) sua modalidade negativa, "ou mais frequentemente ambivalente" da transferência. Roudinesco (2000, p. 51) avalia que as mais diversas escolas de psicoterapia têm em comum o fato de contornarem os três conceitos de Freud que norteiam e definem o campo psicanalítico: o inconsciente, a sexualidade e a transferência:

As psicoterapias substituem o inconsciente freudiano por algo da ordem de um subconsciente biológico; não mais situada como conflito psíquico, a sexualidade é interpretada através do crivo culturalista ou biológico; a transferência é reduzida a uma relação dual calcada na maestria e na sugestão.

Ora, dispor desses conceitos como fundamentais permitiu justamente a Freud avançar por caminhos sempre denegados na prática clínica: "Nas formas tratáveis de psiconeuroses, [a transferência negativa] encontra-se ao lado da transferência terna muitas vezes dirigida simultaneamente sobre a mesma pessoa, um estado de coisas para o qual Bleuler cunhou o bom termo de ambivalência" (Freud, 1998a/1912, p. 115). E são justamente essas manifestações de ambivalência que, se tornando "o instrumento principal da resistência" (Freud, 1992/1925, p. 89), guarda o maior interesse e requer vigilância constante em todo tratamento analítico digno desse nome.

Em troca, ali onde falta essa disposição à transferência de sentimento, ou então onde ela se tornou totalmente negativa, como "na demência precoce ou na paranoia", fica excluída a possibilidade de se exercer influência psíquica sobre o paciente (Freud, 1992/1925). Com sua costumeira e conhecida honestidade e franqueza intelectual, Freud escreve em suas conferências durante a grande guerra de 1914: "Encontramo-nos aqui diante de um fato que não compreendemos e que [...] também nos faz duvidar de ter compreendido verdadeiramente, em todas as suas condições, o sucesso que era possível nas outras neuroses" (Freud, 2000/1915-1917, p. 455). Parte da asserção, talvez não a mais importante, remonta a 1905: "As psicoses, os estados de confusão e de humor depressivo profundo (eu diria de bom grado: tóxico), são [...] impróprias à psicanálise, $a o$ menos tal como ela é exercida até aqui" (Freud, 2006b, p. 54 , grifo meu).

É instrutivo levar em conta que, na Viena dos tempos da formação médica de Freud, "havia uma diferença entre os casos que um neurólogo, especialista [como ele], podia tratar e os pacientes de outra maneira mais perturbados, agora chamados de psicóticos, que acabavam nos serviços hospitalares onde trabalhavam psiquiatras" (Roazen, 1996, p. 20). São naturalmente conhecidos, no livro do sonho, relatos de sonhos de pacientes paranoicos; mas é provável que Deschenau (2009) tenha razão - em sua resenha crítica do livro de T.Vincent, A psicose freudiana: a invenção psicanalítica da psicose, ao sublinhar que os estudos das patologias neuróticas deram a Freud o apoio para sua concepção teórica da psicose, cuja apreensão tem de particular 
o fato de se fazer na teoria, o que impõe limites à sua dimensão terapêutica. Sem jamais se furtar a interrogar sobre os limites dessas teorias, mas participando de toda maneira de sua evolução, é certo que o exercício da psicanálise se fazia com Freud no consultório particular, onde muito raramente era levado a receber pacientes psicóticos. Suas reflexões teóricas se nutriam, portanto, neste particular, de textos escritos, e não da própria experiência clínica.

\section{Sugestão e psicanálise}

A decisão de abandonar o método da "sugestão hipnótica" - antes mesmo da própria hipnose, utilizada no tratamento catártico - é, sem dúvida, uma conquista, mesmo a primeira de uma série. Desde 1892, Freud (1966a/1892-1894) tem experiência suficiente para afirmar a contradição intolerável entre a negação desmesurada da doença, implícita na utilização mesma da técnica sugestiva, e a constatação necessária da realidade dessa mesma doença fora da sugestão.

Anos mais tarde, em sua história do movimento psicanalítico, retomaria o mesmo raciocínio com alguns esclarecimentos adicionais. Clinicamente, o "tratamento pela sugestão hipnótica" mantinha a carga de preconceitos próprios de toda intervenção médica de seu tempo: "Você não tem nada", parecia dizer o médico hipnotizador ao paciente, "é somente nervoso, e é por isso que, aliás, posso dissipar seus aborrecimentos com algumas palavras e em alguns minutos" (Freud, 2000/1915-1917, p. 467). Com essa atitude grosseira, quase insultuosa para com o doente - ainda que um passo à frente da suspeita médico-psiquiátrica de simulação, também no século XIX -, não se fazia mais do que reprimir algo existente em sua vida anímica, reforçando e deixando inalterados todos os processos que levam à formação dos sintomas. Ora, nesse contexto, a prática clínica herdada de Breuer que consistia em investigar os pacientes em estado hipnótico, combinando um "modo de ação automático e satisfação simultânea do desejo de saber", era, sem dúvida, como rememora Freud (2005/1914, p. 252) em 1914, incomparavelmente mais atraente que "a monótona e violenta interdição sugestiva que desviava de toda pesquisa". Enfim, em 1921, portanto, depois de um já longo itinerário, Freud (1991a) daria indicações precisas sobre a maneira de resolver seu velho e fundante problema: o que é a sugestão; qual é sua natureza, sua estrutura, suas propriedades; como a definir?
Tudo começa em 1888 quando traduz para o alemão o livro de Bernheim sobre o tema. Conta a W. Fliess (então um amigo recente e em parte seu futuro sujeitosuposto-saber ao longo da fundação da psicanálise) ter empreendido este trabalho "a contragosto" e, previsão certeira, “[...] somente para ficar como parte interessada num assunto que não deixará de influenciar profundamente, nos próximos anos, a prática dos neurólogos". Expõe claramente sua posição: "Não compartilho das opiniões de Bernheim, que me parecem estreitas, e tentei no prefácio salvar o ponto de vista de Charcot. Ignoro se o fiz com habilidade. Mas eu sei que, com certeza, sem grande sucesso" (Freud, 2006d/1887-1904, p. 38). Freud refere-se aqui à disputa científica travada entre Charcot (Paris) e Bernheim (Nancy) no fim dos anos 1880: grosso modo, o primeiro defendia o caráter fisiológico da hipnose, cuja manifestação mais leve constituiria a sugestão; o segundo, seu caráter psicológico, isto é, a hipnose como um efeito ou um produto da sugestão. Pode ainda nos interessar nessa disputa perdida na poeira dos tempos a posição de Freud, ambígua e jamais conclusiva Strachey (Freud, 1966b/1888-1889). Tal reserva explica-se, primeiro, pelo risco de a teoria da sugestão ser utilizada pelos partidários da "histeria como simples simulação", ideia contra a qual seu mestre Charcot havia tanto lutado nos últimos anos de vida; a fortiori, ao mesmo tempo em que reconhecendo a justeza dos pontos de vista de Bernheim nessa disputa, Freud insurge-se contra a tendência geral de tudo explicar a partir da sugestão. Segundo Gregory Zilborg (apud Masson, 1986/1887-1904, p. 25), Bernheim teria escrito que "passamos a maior parte de nossas vidas alucinando potencial ou realmente as pessoas". Enfim, Freud chegará, em 1921, a uma posição definitiva, e esta sancionará sua oposição... ao psiquiatra de Nancy.

Já na mesma carta a Fliess no longínquo ano de 1888, escreve com evidentes preocupações políticas: "A teoria sugestiva, isto é, iatrossugestiva, de Bernheim é um common-place que exerce sua magia sobre os médicos alemães, que não têm necessidade de dar um grande passo para passar da teoria da simulação, à qual presentemente estão ligados, à teoria da sugestão". E conclui realista a respeito de seu prefácio:

Porque assim o exigia o estado de espírito de todos os meus amigos, tive que moderar a minha crítica a Meynert, que, no estilo insolente e maldoso seu costumeiro, se fez ouvir aqui de maneira autoritária sobre um assunto do qual nada sabe. Apesar 
de tudo, o que escrevi lhes parece uma audácia (Freud, 2006d, p. 38-39).

Em dois de junho daquele mesmo ano, em conferência na Sociedade dos Médicos, Maynert havia recusado o caráter científico dos "fenômenos hipnóticos", afirmando - o que, como veremos mais à frente, não seria do desagrado de Freud - ser a hipnose "a expressão de uma escravização do homem por outros homens" (Freud, 2006d/1887-1904, p. 39). No seu prefácio, conclamava os médicos alemães a levar em conta apenas a experiência, "jamais a autoridade sem a experiência, que no fim leva a escolher a aceitação ou a rejeição" (Freud, 2006d/1887-1904, p. 39)

Duas décadas mais tarde, no caso Hans, Freud (1998b/1909, p. 91) testemunharia em seu próprio favor: "Como é curioso; sou capaz de me lembrar, quando comecei a me imiscuir na querela das opiniões científicas, da zombaria com a qual foi então acolhida pela velha geração dos neurólogos e dos psiquiatras a tese da sugestão e seus efeitos". Ao constatar algo da ordem de uma virada de paradigma, ele parece dar prosseguimento direto ao comentário de 1888: "Desde então, a situação mudou radicalmente; a repugnância primitiva converteu-se muito facilmente numa aceitação complacente [...]". Não duvidaria mais em seguida dos efeitos produzidos pela influência da escola de Nancy no decorrer daqueles anos; mas esta pronta aceitação antes se devia, repreende Freud (1998b/1909, p. 91), a uma tomada de consciência de existir uma espécie de "economia de pensamento" ao se empregar esta palavra para qualquer coisa. Sua conclusão é ao mesmo tempo uma crítica notável e um esquema preciso das intenções e decisões científicas: "Com efeito, ninguém sabe nem se preocupa em saber o que é a sugestão, de onde ela provém e quando ela se instala; é suficiente que se possa chamar de 'sugestão' tudo o que é incômodo no psiquismo".

Em 1921, quando em Psicologia das massas e análise do eu interroga-se sobre a causa da influência exercida pela massa sobre o sujeito, de maneira tal que este passa a ter suas funções psíquicas profundamente alteradas, decepciona-se mais uma vez ao verificar em todos os autores uma explicação comum: "a palavra mágica sugestão" (Freud, 1991a, p. 27). A advertência é antiga: na tradução do livro de Bernheim, Freud já apontava esta particularidade segundo a qual, explicando todos os fenômenos, era a própria sugestão que permanecia inteiramente inexplicável e encoberta por uma demonstração exagerada da necessidade de prescindir de ser explicada (Freud, 1996a/1888-1889). Na obra de 1921, confessa sua "revolta contra o fato de a sugestão, que explica tudo, dispensar-se ela própria de explicação" (Freud, 1991a/1921, p. 28). A noção, que parece acompanhá-lo como sombra ao longo da construção de sua disciplina (“... depois de um afastamento de 30 anos, me aproximo outra vez do enigma da sugestão...”), diz respeito, a uma vaga "aptidão à sugestão", como defendia Bernheim, que por sua vez permanecia como sendo um fenômeno originário, um fato fundamental (Grundtatsache) e irredutível da alma humana (Freud, 1991a/1921). Por duas vezes, em 1889 e em 1921, Freud faz uso da mesma "velha adivinhação" para descrever o problema: "Cristóvão carregava Cristo, Cristo carregava o mundo inteiro. Diga-me então onde Cristóvão se apoiava?" (Freud, 1966c/1889, p. 101; Freud, 1991a,1921, p. 28, respectivamente).

Além da advertência quanto à imprecisão conceitual do termo, outro aspecto da clínica de Bernheim, denunciado por Freud (1991a, p. 28) na obra de 1921, merece consideração:

\footnotetext{
Também não perdi a lembrança de minha surda oposição [...] a essa tirania da sugestão”. Na clínica, naturalmente: "Quando se invectivava sobre um doente, que não se mostrava dócil: 'o que está fazendo? Você se contrassugestiona!', eu me dizia que havia ali injustiça patente e ato de violência. O homem tinha certamente direito a contrassugestões, quando tentavam assujeitá-lo com sugestões.
}

Essa posição parece contrariar em parte a afirmativa de Stengers (1989) segundo a qual Freud teria rejeitado a hipnose e modificado o uso da sugestão por motivos não éticos, mas técnicos. Afinal, teria sido justamente este, conforme ele próprio, um ponto de litígio com a escola suíça: "Nós recusamos deliberadamente fazer do paciente [...] nosso bem próprio, traçar para ele seu destino, lhe impor nossos ideais e, com o orgulho do criador, modelá-lo à nossa imagem [...]" (Freud, 1996b/1919, p. 105). Tudo ao contrário também do que propunha o americano Putnam, um "amigo dileto", mas para quem a psicanálise "[se colocaria] a serviço de uma determinada visão do mundo filosófica", impondo-a ao paciente com o fim de enobrecê-lo: "Deixe-me dizer haver aí [...] apenas violência", desautoriza firmemente Freud tal disparate clínico, "mesmo 
se ela estiver coberta pelas intenções mais nobres" (Freud, 1996b/1919, p. 106).

Na realidade, ambos os motivos - éticos e técnicos - são congruentes, assim como também aqueles de ordem teórico-epistemológicas. É verdade que em relação à sugestão e à hipnose sua abordagem teórica deixará de interessar Freud durante numerosos anos (e, quando isso ocorre, será sempre um tema à côtê). Já a questão ética teria um rápido desfecho, ou ao menos uma abordagem promissora, com o estabelecimento do próprio método psicanalítico: entre 1896 e 1897, ao abandono da sugestão direta seguese ao da própria hipnose, e enfim a adoção da livre associação - não necessariamente uma após a outra. De toda maneira, não pratica "a hipnose para fins terapêuticos [...], escreve em 1905, há cerca de oito anos [...] (salvo para algumas experiências isoladas) [...]" (Freud, 2006b, p. 50). Construído o método psicanalítico, cabe justificá-lo em sua singularidade, fundamentando-o, sobretudo, em suas diferenças.

\section{Sugestão e transferência}

Em 1909, defendendo a objetividade da análise de Hans e em resposta à consideração de que o paciente, uma criança, seria altamente sugestionável, mais uma vez Freud denuncia o emprego abusivo da palavra "sugestão": aqueles que agem assim simplesmente evitam ou recusam pensar sobre o que é a sugestão, de onde ela emana e quando ela se estabelece. Ainda em 1909, mas numa de suas conferências americanas (publicadas em 1910), pela primeira vez e de passagem estabelece a relação: "O estudo da transferência pode também lhes dar a chave para compreender a sugestão hipnótica, da qual inicialmente nos servimos como meio técnico para a exploração do inconsciente [à maneira de Breuer e não de Charcot ou Bernheim] em nossos doentes" (Freud, 1993/1910, p. 51).

É suficientemente modesto para admitir que por hora tem pouco a dizer sobre a própria transferência, e não fará mais do que traçar seus contornos teóricos fundamentais. Com este nome, e naquele momento (1910) de sua obra, refere-se às "transferências" (no plural) de sentimentos ternos e amáveis com frequência misturados a sentimentos de hostilidade dirigidos pelo paciente ao analista. Esses sentimentos não têm sua fonte ou sua razão de ser em qualquer experiência real entre ambos, logo, por suas particularidades, parecem provenientes de antigos desejos inconscientes do paciente. Além disso, supõe-se que, na relação com o analista, ele reviva parte de sua vida amorosa, resistindo em recordá-la na análise. Este acontecimento, aliás, vivido como uma atualidade irreversível é que o convence da realidade de suas representações sexuais recalcadas. $\mathrm{O}$ analista parece realizar - e aqui Freud figura o processo analítico como uma reação química - o papel de um "fermento catalisador", expressão “excelente", diz ele, creditando-a a Ferenczi (1968a/1909, p. 96). Enfim, a transferência é um fenômeno universal e espontâneo em todas as relações humanas (Freud, 1993/1910, p. 51), mas que decide o sucesso da influência médica. Sua consideração atenta e rigorosa - de fato, como referido mais adiante, na forma de uma "neurose de transferência" artificialmente criada - constitui o diferencial clínico-epistemológico do campo psicanalítico. A relação hipnótica, alternativa eminentemente terapêutica, impedia o conhecimento científico da questão porque deslocava as resistências psíquicas de uma região para em seus confins acumulá-las como muralha intransponível (Freud, 1993/1910, p. 23).

Será, ao final de suas Lições de introdução à psicanálise (1915-1917), que a relação entre a sugestão e a transferência será retomada para descrever a faculdade reconhecida em todo homem normal de investir a energia libidinal sobre pessoas. A disposição à transferência, constatada entre os neuróticos, não constituiria senão um excesso extraordinário dessa faculdade geral. "Seria [...] muito estranho que um traço do caráter humano tão disseminado e significativo jamais tivesse sido notado nem explorado" (Freud, 2000/1915-1917, p. 462). Menciona Bernheim - um desses observadores de "perspicacidade infalível", cuja doutrina dos fenômenos hipnóticos fundou-se na tese segundo a qual, de uma maneira ou de outra, todos os homens são "aptos à sugestão, sugestionáveis" - antes de explicar que "sua sugestionabilidade não [seria] outra coisa que a disposição à transferência tomada num sentido muito restrito, de modo a que nela não tivesse lugar a transferência negativa". Bernheim, afirma Freud (2000/1915-1917, p. 463), jamais pôde dizer "o que é de fato a sugestão e como ela se produz" e jamais reconheceu a dependência da "sugestionabilidade" em relação à sexualidade, à atividade da libido.

Trata-se, então, de abordar esta operação pela qual a sugestão manifesta-se em forma de transferência. Primeiro, levando em consideração a disposição à transferência, comecemos por distinguir, com ele, duas modalidades de investimento libidinal: a libido 
pode tomar por objeto o próprio sujeito (libido do eu ou narcísica) ou um objeto exterior (libido de objeto). Pressupõe-se sempre entre os dois um balanceamento energético de tal maneira que a segunda diminui quando a primeira aumenta, e vice-versa. Assim, em circunstâncias normais, a libido pode ser transformada sem nenhum impedimento em libido objetal e esta pode novamente retornar ao eu (tomado aqui como reservatório de libido). O sujeito dispõe, portanto, de uma quantidade de energia a repartir de maneira variável entre seus objetos e si mesmo. No estado de sono, por exemplo, há como que uma supressão de todo interesse pelo mundo exterior - ou seja, há um refluxo da libido objetal para o eu daquele que dorme. Alguma coisa de similar parece ocorrer em certos estados psicóticos e melancólicos. “A observação mostra que os doentes atingidos de neuroses narcísicas [...] recusam o médico, não por hostilidade, mas por indiferença. [...] neles o investimento [deve] ter sido abandonado e a libido de objeto, transposta em libido do eu" (Freud, 2000/1915-1917, pp. 463-464).

O inverso se passa no estado amoroso ou de paixão [Verliebtheit]: uma grande parte da libido narcísica investe o objeto amado de tal maneira que o mundo exterior parece adquirir um interesse subitamente novo. Na hipnose, esse estado amoroso torna-se ainda tão mais intenso e evidente que a explicação do estado hipnótico parece a Freud melhor esclarecer o estado amoroso, e não o inverso. Tal disposição à transferência é, desde então, a expressão radical de uma característica universal, constitutiva e estruturante no desenvolvimento da sexualidade humana. Em dado momento, o infans - até então mergulhado em atividades autoeróticas - tem suas pulsões sexuais reunidas com o fim de encontrar no exterior um objeto amoroso. Como num ensaio, toma-se primeiro a si próprio como este objeto (narcisismo primário), para em seguida dirigir seus investimentos para o outro, seu semelhante.

Sublinhemos, mais uma vez: esta faculdade de investir libidinalmente no outro, Freud chama de disposição à transferência, cuja intensificação nos neuróticos a observação clínica permite verificar. "O doente busca antes de tudo a satisfação substitutiva no próprio tratamento, na relação de transferência sobre o médico [...]" (Freud, 1996b/1919, p. 104), enquanto antes as buscava na doença. Tal deslocamento de investimento libidinal caracteriza, na análise, a neurose de transferência recente, que assim substitui a neurose anterior (Freud, 1996a/1920, p. 289). Sem lhe ser possível lembrar-se de tudo que nele é recalcado, e "precisamente do essencial", vê-se "obrigado a repetir o recalcado como experiência vivida no presente, em vez de se lembrar dele como uma parte do passado". Eis aqui a reviravolta analítica: "Quando o tratamento é levado até este ponto, podemos dizer que a neurose anterior é agora substituída por uma neurose de transferência..." (Freud, 1996a/1920, p. 289).

Vale sublinhar que somente nesse sentido - não nosográfico, mas clínico - a transferência, fenômeno universal, é gerada pela situação analítica. Como tal, a ideia de uma neurose de transferência, se praticamente relegada hoje ao ostracismo na clínica psicanalítica atual, integra como noção um lugar importante na teoria clínica freudiana. Enfim, o raciocínio esclarece retroativamente o fato de que a formação dos sintomas neuróticos é francamente motivada por forças de natureza sexual (Freud, 1991b/1923, p. 196).

\section{Sugestão ou transferência}

Vemos assim que vinculando a questão da sugestão à questão sexual Freud dá certamente um passo à frente em relação a Bernheim, que, desconhecendo sua origem e a forma de sua produção, contenta-se em considerá-la como um fato fundamental. De sua parte, a investigação analítica permite reconhecer a sugestão como a parte positiva do fenômeno de transferência, que, como tal, "subsiste e é para a psicanálise, tanto como para outros métodos de tratamento, o condutor de sucesso" (Freud, 1998a/1912, p. 57). Contudo, assinala ser conveniente dar ao termo sugestão o sentido atribuído por Ferenczi e ele próprio, isto é, "a influência exercida sobre um ser humano por meio dos fenômenos de transferência que nele são possíveis" (Freud, 1998a/1912, p. 114). Há aqui uma idiossincrasia metodológica e epistemológica da psicanálise, ao reconhecer um limite além do qual essa influência vai sempre de encontro à resistência do sujeito; em contrapartida, essa resistência tem na análise uma função heurística. Enfim, o destaque é dado ao paciente, não a um suposto poder mágico do terapeuta.

Compreende-se assim a razão pela qual a terapia hipnótica mostrava-se contingente, aleatória, duvidosa. Sendo um tratamento infinitamente mais rápido que o tratamento analítico, sem maiores inconvenientes e dificuldades para o paciente (tuto, cito, incunde, como na fórmula clássica da medicina tradicional), seu ritual tornava-se, contudo, monótono e cansativo para o médico, pois, sempre o mesmo, consistia 
em proibir a todo sintoma de existir, sem buscar-lhe sentido e motivação. "Era um trabalho de manobra [Handlangerarbeit], diz Freud (2000/1915-1917), não uma atividade científica, fazendo pensar mais na magia, na encantação, no abracadabra" (p. 466). Sobretudo, não era confiável sob outros aspectos. Alguns pacientes se deixavam influenciar, outros, não, e em todos os casos, ninguém compreendia o porquê; e as curas presumíveis eram não só inexplicáveis como jamais permanentes.

Ferenczi, que nos últimos anos de sua vida teria sido inteiramente tomado pelo interesse pela técnica (Balint, 1968), sublinha justamente que esses dois obstáculos - o fato de "todos não poderem ser sugestionados", bem como o caráter provisório desta influência-teriam impedido a terapêutica pela hipnose e sugestão de se tornar um "procedimento maravilhoso" (Ferenczi, 1968b/1912, p. 234). Todo cuidado é assim necessário para não se deixar levar por esta até certo ponto justificada tentação.

Em uma palavra, como tantos psicoterapeutas ainda hoje, Bernheim não sabia que, por definição, a utilização da hipnose, apoiada no estado e na capacidade de transferência do paciente, depende essencialmente do aspecto positivo dessa transferência, que provisoriamente coloca em suspenso a ambivalência pulsional. Ora, para infortúnio de sua opção empirista e carente de modelos teóricos, as reações do paciente se manifestavam em sua singularidade fantasmática, o que demanda um estudo caso por caso - segundo Freud, efetuando sobre a transferência um trabalho de investigação, em vez de tratá-la como simples instrumento auxiliar cuja importância se esgota no fato mesmo de sua existência. Recusando-se a considerá-la como algo dado, ele sabe que por conta da estreita relação com a resistência e a repetição sua manifestação clínica está sujeita a uma oposição própria dos limites afetivo-transferenciais de cada um.

Seria, então, o caso de perguntar: a que ponto? Variando "do estado amoroso passional plenamente sensual à expressão extrema da revolta, do rancor e do ódio" (Freud, 1992/1925, p. 88), é também possível considerar na transferência alguma especificidade nosográfica ou estrutural. Por exemplo, sob seus efeitos as histéricas podiam imaginar-se grávidas, como Anna O., desejarem ser beijadas por Freud, ou, até mesmo, frente à inabilidade do analista, abandonar a análise, como Dora... Já o Homem dos ratos, neurótico obsessivo, numa sessão "repleta da transferência mais assustadora, [...] experimenta, por exemplo, uma enorme dificuldade em contar" que um dos irmãos de Freud teria cometido um assassinato em Budapeste. Lembrando-se imediatamente de Leopold Freud, "o assassino do trem", de quando cursava o terceiro ou quarto ano da escola, Freud, rindo, lhe pergunta de onde havia tirado aquela história. Como resposta, o paciente revela "ter sido seu cunhado, conhecido de meu irmão, que lhe contou para provar que a educação não quer dizer nada e a predisposição, tudo". Freud então lhe assegura não ter parentes em Budapeste: "Aliviado, [o Homem dos ratos] confessa que por esta razão vinha, desde o início, com certa desconfiança" (Freud, 1974/1955, pp. 159-161).

A Ferenczi, Freud escreve sobre o Homem dos lobos, em 13 de fevereiro de 1910: "Um jovem russo, rico, que eu atendo por causa de uma paixão amorosa compulsiva, confessou-me depois da primeira sessão as seguintes transferências: judeu bandido, ele gostaria de me pegar por trás e me cagar na testa". Segundo Freud, seu primeiro sintoma manifesto, aos seis anos de idade, "consistia em injúrias blasfematórias contra Deus: porco, cachorro, etc. Sentia-se incomodado quando via na rua três montes de merda por causa da S. [anta] Trindade, e ansiosamente buscava um quarto [monte] para destruir a evocação" (Freud, \& Ferencsi, 1992/1908-1914, p. 149).

Desconfiança, culpabilidade, pensamentos fantasiosos de morte, de crueldade, de ódio; escatológicos, privados e íntimos, cujo alvo é (só) aparentemente o analista. A ação do analista, por sua vez, será determinada por sua capacidade de se fazer instrumento de deslocamento e de substituição e de como acolher o diabo, depois de cutucá-lo com vara quase sempre curta.

As lições introdutórias de psicanálise, de 1915-1917, estabelecem explicitamente pela primeira vez na obra freudiana os limites da sinonímia entre a sugestão hipnótica (no sentido próprio e figurado) e a sugestão analítica. Se ao mesmo tempo temos entre a sugestão e a transferência uma espécie de equivalência e uma distinção, foi para esta última que mais se dirigiu o interesse de Freud, visando a construir o conceito de transferência em absoluta consonância com a direção do tratamento analítico: "Ao longo de sua vida", observa Le Guen (1989, p. 14), "ele esteve atento para reexaminar e situar o lugar da sugestão na ação terapêutica, não para combatê-la, mas para isolar o núcleo duro que lhe parece 'o ouro puro da psicanálise'. Levando em conta que, à diferença de Bernheim, Freud logra explicar a natureza da sugestão (isto é, como a parte positiva da transferência), é pertinente e útil observar a diferença de método existente entre as suas formas 
de tratamento - a sugestão hipnótica e a analítica. Mais particularmente a maneira como cada uma delas utiliza o fator da sugestão em seu próprio benefício.

Seu raciocínio começa em 1905, quando, depois de afirmar a maior oposição entre ambos os tratamentos, parafraseia a célebre fórmula com a qual Leonardo da Vinci confronta a pintura à escultura. Como na primeira, que procede per via di porre - ou seja, aplicando cores em quantidade sobre a tela branca - a técnica sugestiva, aplica algo sobre a doença, a sugestão, esperando que esse procedimento seja poderoso o suficiente para impedir "a manifestação da ideia patogênica". A técnica analítica, ao contrário, procede per via di levare, e como na escultura, que "remove da pedra tudo que ainda recobre a superfície da estátua nela contida [...], não quer introduzir nada de novo", mas remover, retirar; além disso, "preocupa-se com a gênese dos sintomas mórbidos e com o contexto psíquico da ideia patogênica que ela tem como alvo suprimir" (Freud, 2006b/1905, p. 51, grifo meu).

Uma dezena de anos mais tarde, "à luz dos conhecimentos que adquirimos com a psicanálise", continua a afirmar que a terapia hipnótica busca dissimular e maquiar algo da vida anímica - ela trabalha como uma "cosmetologia" -, utilizando a sugestão para proibir os sintomas e reforçando assim os recalcamentos. A análise - que trabalha como uma "cirurgia" - utiliza a sugestão para modificar a saída dos conflitos que deram origem aos sintomas, convicta de que, apenas em presença dos primeiros, os segundos podem ser eliminados. Enfim, em vez de manter o paciente inerte e passivo como no tratamento hipnótico, a análise o incumbe da parte substancial do trabalho - na realidade (o que não é óbvio, como intramuros à primeira vista pode parecer) é o analisando quem faz sua análise. Evidentemente que tal processo exige, dele e do analista, grandes esforços para ultrapassar suas resistências inconscientes: “[...] o peso principal recai sobre as resistências do doente; toda a arte [é] agora colocá -las a descoberto o mais rápido possível, mostrá-las ao doente e incitá-lo (é aqui que se situa a sugestão agindo como 'transferência') a abandonar suas resistências" (Freud, 1996a/1920, p. 288). Em contrapartida, os resultados são permanentes e ele se acha protegido da possibilidade de uma recaída.

Insistindo uma vez mais sobre os limites do fator da sugestão - afinal, são eles que no tratamento determinam a ação do analista-, Freud assegura que a clínica psicanalítica mantém uma atitude muito reservada (prudente, pode-se acrescentar) em relação aos sucessos obtidos rapidamente, vendo-os muito mais como obstáculo do que como ajuda ao trabalho de análise. "Aqui não invocamos-sugestão ou transferência-para decidir sobre o sucesso terapêutico", escreve em 1925 (Freud, 1992/1925, p. 89), e tal postura livra os resultados da análise da suspeita de serem bemsucedidos em virtude da sugestão, pois ocorre que, com ela, o paciente é levado ao trabalho psíquico de ultrapassar as resistências. Sobretudo, "trabalhamos sobre a própria transferência, dissolvemos o que a ela se opõe, desenvolvemos o instrumento com o qual queremos agir", enquanto que em qualquer outro tratamento sugestivo a transferência é cuidadosamente poupada. Com esta opção, torna-se possívelà psicanálise "retirar do poder da sugestão outro proveito; [...] não é o doente que se sugestiona como bem entende, mas somos nós que guiamos sua sugestão, ao menos na medida em que é acessível à sua influência" (Freud, 2000/1915-1917, p. 468). Para Stengers (1989, p. 185), com quem desta vez é possível concordar, "com o manejo da transferência, Freud não abandonou o uso da sugestão. [...] a diferença entre sugestão usual e sugestão analítica deve-se ao caráter controlável e calculável desta última".

Freud não evita expor a objeção mais frequentemente levantada contra sua disciplina, segundo a qual tanto faz chamar de transferência ou sugestão a força pulsátil da análise e, assim, igualando tudo, considerar "a influência exercida no paciente como argumento para tornar duvidosa a certeza objetiva de nossas descobertas" (Freud, 2000/1915-1917, p. 468). Tal objeção, embora pouco pertinente, tampouco lhe parece despropositada, pois, afinal, ela existe igualmente naqueles que desconfiam da significância das experiências sexuais dos pacientes, ou da existência mesma dessas experiências, acreditando que lhes teriam sido antes inculcadas pelo analista.

Ora, não seria difícil para o analista fazer do paciente um adepto de uma determinada teoria ou mesmo torná-lo cúmplice de alguns de seus erros. Sob este aspecto, o paciente se comportaria como qualquer outra pessoa - como um aluno, por exemplo. Mas isso atingiria "apenas sua inteligência, e não sua doença” (Assoun, 1988, p. 69). Quero supor que o paciente não encaminhará a bom termo seus conflitos nem terá diminuídas suas resistências, a menos que as intervenções do analista, à maneira de representações de expectativa ou de espera (Erwartungsvorstellungen), revelem-se justas frente à realidade patente de seu infortúnio e mal-estar pessoal. "A Erwartungsvorstellung, escreve Assoun, 
1988, p. 75, é [...] uma espécie de imagem a ser preenchida [afetivamente] de conteúdo quando o sujeito a tiver investido, para dar-se conta de que efetivamente ali tem algo de 'importante' a ser visto”. É, portanto, uma coisa diversa de uma "banal sugestão - ainda que isso confirme a persistência de um momento sugestivo na relação analítica [...]" (Assoun, 1988, p. 75), algo que os próprios analistas não têm o direito de esquecer.

\section{Para concluir}

Haveria em nós essa "necessidade premente", invocada por Kant, segundo a qual somos incapazes de "nos impedir de supor a existência de um ser supremo, para além do sensível, como causa de nosso mundo e garantia de sua coerência"? Uma "necessidade de servidão", conforme apontaram Maquiavel, La Boétie, Hobbes e Sade, e já referida por Platão, em A República, como uma dificuldade dos homens de suportar sua liberdade, responsável em parte pela constituição da tirania? Enfim, tenderíamos a nos aproximar dos mestres capazes de "nos transmitir um saber sobre uma verdade que excede o conhecimento" (Marie, 2004, p. 164-165)?

Se assim for, tais premissas sustentariam igualmente a disposição à transferência em todo tratamento psíquico. Sem estar livre de tantos e tais perigos, os procedimentos clínicos da psicanálise se contrapõem, no entanto, aos das psicoterapias na medida em que estas, por definição, convictas de um saber "universal", inscrevem o sintoma exposto pelo paciente numa grade de leitura capaz de fornecer sua significação, para assim conceber seus métodos e protocolos de remissão de sintomas, cujo objetivo é assegurar o bem dos pacientes e promover sua felicidade. Adicione-se que as psicoterapias - ao contrário da psicanálise freudiana, que não é uma filosofia - assentam-se assim na ideia de haver um sentido, de ter a vida um sentido, visando à concretização de uma possível harmonia. Pois justamente aqui mora o

\section{Referências}

Assoun, P.-L. (1988). Freud et Wittgenstein. Paris: P.U.F. Balint, M. (1968). Présentation. In: Ferenczi, S. Psychanalyse (tome I). Paris: Payot.

Deschenau, A. (2009). La psychose: quelle place dans la psychanalyse de Freud? Nonfiction.fr : le quotidien des livres et des idées. Recuperado de http://www.nonfiction.fr/article-3008-p2-la psychose__quelle_place_dans_la_psychanalyse_de_freud_htm perigo: como adverte Marie (2004, p. 22), "todo sofrimento psíquico induz à ideia de haver em algum lugar um saber sobre ele". E é este saber que, circunscrito numa dada pessoa, suscita o amor que temos por ela "[tornando-nos] doravante sensíveis a seus propósitos". Por isso, conforme ainda o raciocínio de Marie (2004, p. 22), o amor é igualmente "o limite da ação de toda psicoterapia".

Lemos em Freud (2000/1915-1917, p. 146): "A crença repete [...] a história de sua própria gênese: [...] ramificação do amor", esta crença nem mesmo tem "necessidade dos argumentos". Mais de dez anos antes, nos Três ensaios..., já mostrara a importância, e talvez mesmo a essencialidade da "credulidade do amor" como fonte da autoridade, citando mesmo, como exemplo, a docilidade crédula dos hipnotizados para com os hipnotizadores, de resto, verificada igualmente na "cegueira lógica" dos apaixonados diante dos julgamentos emitidos pelo objeto sexual escolhido (Freud, 2006a/1905, p. 83).

Podemos enfim supor, a título de conclusão, que todo tratamento psíquico fundado apenas na sugestão (essencial ou circunstancial) sustenta-se na condição limite de um amor impossível, pois supostamente destituído de ambivalência. Aliás, é justamente esse desprezo pela ambivalência pulsional que sustenta, sempre ilusoriamente, não só o estado de paixão amorosa como qualquer outra paixão que na vida se constitua como única e exclusiva para o sujeito. Por exemplo, a paixão ideológica, qualquer ideologia, e em particular, a político-religiosa, que em nossa contemporaneidade tem sido capaz de se mostrar de tantas maneiras chocante e ameaçadora.

Nesses tempos em que se configuram inéditas possibilidades de trabalho nas redes e sistemas públicos de saúde do país, o profissional de Psicologia (psicanalista ou não) se verá cotidianamente confrontado em sua clínica às questões aqui esboçadas, como realidade imanente, intrínseca e incontornável de seu ofício. Necessariamente, esperamos todos, escolhas hão de se fazer por aí.

Ellenberger, H. F. (1994). Histoire de la découverte de l'inconscient. Paris: Fayard.

Ferenczi, S. (1968a). Transfert et introjection. In S. Ferenczi, Psychanalyse I. Paris: Payot. (Orginal publicdo em 1909)

Ferenczi, S. (1968b). Suggestion et psychanalyse. In S. Ferenczi, Psychanalyse I. Paris: Payot. (Original publicado em 1912)

Freud, S. (1966c). Review of Auguste Forel's hypnotisme. In S. Freud, The standard edition of 
the complete psychological works of Sigmund Freud. London: Hogart. (Original publicado em 1889)

Freud, S. (1966b). Preface to the translation of Bernheim's suggestion In S. Freud, The standard edition of the complete psychological works of Sigmund Freud. London: Hogart. (Original publicado em 1888-1889)

Freud, S. (1966a). Preface and footnotes to the translation of Charcot's tuesday lectures In S. Freud, The standard edition of the complete psychological works of Sigmund Freud. London: Hogart. (Original publicado em 1892-1894)

Freud, S. (1974). L'homme aux rats: journal d'une analyse. Paris: PUF. (Original publicado em 1955)

Freud, S. (1991a). Psychologie des masses et analyse de moi (CEuvres complètes, Vol. 17). Paris: P.U.F. (Original publicado em 1921)

Freud, S. (1991b). «Psychanalyse» et «théorie da libido» (CEuvres complètes, Vol. 16). Paris: P.U.F. (Original publicado em 1923)

Freud, S. (1992). Autoprésentation (CEuvres complètes, Vol. 17). Paris: P.U.F. (Original publicado em 1925)

Freud, S. (1993). De la psychanalyse (Euvres complètes, Vol. 10). Paris: P.U.F. (Original publicado em 1910)

Freud, S. (1996b). Les voies de la thérapie psychanalytique (Guvres complètes, Vol. 15). Paris: P.U.F. (Original publicado em 1919)

Freud, S. (1996a). Au-delà du principe du plaisir (Euvres complètes, Vol. 15). Paris: P.U.F. (Original publicado em 1920)

Freud, S. (1998b). La phobie d'un petit garçon (Euvres complètes, Vo 9). Paris: P.U.F. (Original publicado em 1909)

Freud, S. (1998a). Sur la dynamique du transfert (Euvres complètes, Vol. 11). Paris: P.U.F. (Original publicado em 1912)

Freud, S. (2000). Leçons d'introduction à la psychanalyse (CEuvres complètes, Vol. 14). Paris: P.U.F. (Original publicado em 1915-1917)

Freud, S. (2005). Contribution à l'histoire du mouvement psychanalytique. (Euvres complètes, Vol. 2). Paris: P.U.F. (Original publicado em 1914)

Freud, S. (2006c). La méthode psychanalytique de Freud (CEuvres complètes, Vol. 6). Paris: P.U.F. (1904)

Freud, S. (2006b). De la psychothérapie (Euvres complètes, Vol. 6). Paris: P.U.F. (Original publicado em 1905)
Freud, S. (2006a). Trois essais sur la théorie sexuelle (Cuvres complètes, Vol. 6). Paris: P.U.F. (Original publicado em 1905)

Freud, S. (2006d). Lettres à Wilhelm Fliess. Paris: PUF. (Original publicado em 1887-1904)

Freud, S., \& Ferenczi, S. (1992). Correspondance (Vol. 1). Paris: Calmann-Lévy. (Original publicado em 1908-1914)

Laplanche, J., \& Pontalis, J-B. (1973). Vocabulaire de La psychanalyse. Paris, P.U.F.

Le Petit Robert 1. (1989). Dictionnaire alphabétique et analogique de la langue française. Paris: Dictionnaires Le Robert.

Le Guen, C. (1989). La psychanalyse: une science? In C. Le Guen, La psychanalyse, une science? Paris: Les Belles Lettres.

Mannoni, O. (1980). Un commencement qui n'en finit pas: transfert, interprétation, théorie. Paris: Seuil.

Marie, P. (2004). Psychanalyse, psychothérapie: quelles différences ? Paris: Aubier/Flammarion.

Masson, J. M. (Org.) (1986). A correspondência completa de Sigmund Freud para Wilhelm Fliess. Rio de Janeiro: Imago. (Original publicado em 1887-1904)

Miller, J.-A (1987). Percurso de Lacan: uma introdução. Rio de Janeiro, RJ, Zahar.

Montaigne, M. (1962). De la force de l'imagination. In M. Montaigne, CEuvres complètes. Paris: Gallimard.

Montaigne, M. (1940). De la force de l'imagination. In M. Montaigene, Essais (pp. 110-120). Paris : Pleiade.

Platão. (1989). Ion. Paris: Flammarion.

Roazen, P. (1996). Mes rencontres avec la famille de Freud. Paris: Seuil.

Roudinesco, E. (2000). Por que a psicanálise? Rio de Janeiro: Jorge Zahar.

Stengers, I. (1989). Boîtes noires scientifiques, boîtes noires professionnelles. In C. Le Gue, La psychanalyse, une science? Paris: Les Belles Lettres.

Strachey, J. (1966). Preface to the translation of Berheim's suggestion. In S. Freud, The standard edition of the complete psychological works of Sigmund Freud. London: Hogart. (Original publicado em 1888-1889)

\section{Fernando Aguiar}

Doutor em Filosofia pela Université Catholique de Louvain. Bélgica. Docente da Universidade Federal de Santa Catarina, Florianópolis - SC. Brasil.

E-mail: fernando.aguiar@ufsc.br 


\section{Endereço para envio de correspondência:}

Universidade Federal de Santa Catarina, Centro de

Filosofia e Ciências Humanas, Departamento de

Psicologia. Campus Universitário. Trindade.

CEP: 88040-900. Florianópolis - SC. Brasil.

Recebido 27/11/2015

Aprovado 26/01/2016

Received 11/27/2015

Approved 01/26/2016

Recibido 27/11/2015

Aceptado 26/01/2016

Como citar: Sousa, F. A. B. (2016). Psicanálise e psicoterapia: o fator da sugestão no "tratamento psíquico". Psicologia: Ciência e Profissão, 36(1): 116-129. doi:10.1590/1982-3703004102015

How to Cite: Sousa, F. A. B. (2016). Psychoanalysis and Psychotherapy: Suggestion as a Factor in the "Psychological Treatment”. Psicologia: Ciência e Profissão, 36(1): 116-129. doi:10.1590/1982-3703004102015

Cómo citar: Sousa, F. A. B. (2016). Psicoanálisis y psicoterapia: la sugestión como factor en el "tratamiento psíquico". Psicologia: Ciência e Profissão, 36(1): 116-129. doi:10.1590/1982-3703004102015 